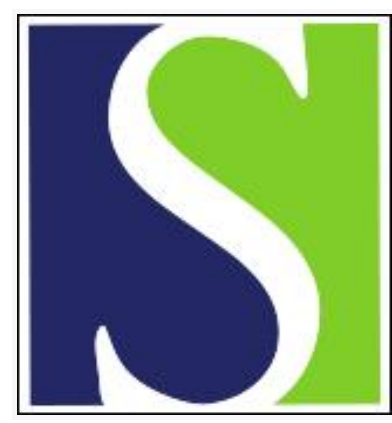

Scand J Work Environ Health 1995;21(3):215-222

https://doi.org/10.5271/sjweh.30

Issue date: Jun 1995

Sources of variance in exposure to nonneutral trunk postures in varying working situations

by van der Beek AJ, Kuiper JI, Dawson M, Burdorf A, Bongers PM, Frings-Dresen MHW

The following articles refer to this text: 2001;27(1):21-29;

2010;36(1):3-24; 2014;40(3):252-265

Key terms: back pain; exposure assessment; lumbar posture; measurement strategy; misclassification; observation; occupational epidemiology; variability

This article in PubMed: www.ncbi.nlm.nih.gov/pubmed/7481609 


\title{
Sources of variance in exposure to nonneutral trunk postures in varying work situations
}

\author{
by Allard J van der Beek, PhD, ${ }^{1}$ Judith I Kuiper, MSc, ${ }^{1,2}$ Mirande Dawson, ${ }^{2}$ Alex Burdorf, PhD, ${ }^{3}$ \\ Paulien M Bongers, PhD, ${ }^{2}$ Monique HW Frings-Dresen, $P h D^{1}$
}

\begin{abstract}
van der Beek AJ, Kuiper JI, Dawson M, Burdorf A, Bongers PM, Frings-Dresen MHW. Sources of variance in exposure to nonneutral trunk postures in varying work situations. Scand J Work Environ Health 1995;21: $215-22$.

Objectives The purpose of this study was to estimate the different components of variance in exposure to nonneutral trunk postures.

Methods The percentages of worktime spent in trunk flexion and trunk rotation or lateroflexion during 10-min observation periods were used as primary measures in analyses of variance to separate the total variance in its components. For two occupational groups six observation periods were selected per worker, and for four other groups 10 periods were used. Most of the 35 subjects were not restricted to one workplace, and they performed dynamic work while being observed.

Results The variance within workers contributed around $80 \%$ to the total variability of exposure to both unfavorable postures. These results indicate that it is difficult to achieve an unbiased estimate of exposure to postural stress for individual workers who perform dynamic tasks in varying work situations.

Conclusions The results indicate that it is difficult to achieve an unbiased estimate of exposure to postural stress for individual workers who perform dynamic tasks in varying work situations. Measurement strategy for exposure assessment requires many repeated observations per worker.
\end{abstract}

Key terms back pain, exposure assessment, lumbar posture, measurement strategy, misclassification, observation, occupational epidemiology, variability.

Several epidemiologic studies have identified flexed, rotated, and lateroflexed work postures of the trunk as risk factors associated with the occurrence of back pain $(1-4)$, but conflicting findings have also been reported $(5,6)$. Given that the prevalence of back pain is of major concern for society, the scientific knowledge is surprisingly limited (7). The scarcity of evidence may partly be caused by attenuation of the association between nonneutral trunk postures and back pain due to nondifferential misclassification of exposure (8). An important determinant of biased estimators of true exposure is variability in exposure (9).

There are two sources of variance in the estimation of exposures at the individual level, the between- and within-worker variance. Between workers who perform the same tasks variability in exposure can be explained by, for example, differences in the workers' anthropometry or work methods (7). For an individual worker the expo- sure to nonneutral trunk postures varies because of the differences between and within tasks. In general, withinworker variance becomes increasingly important when dynamic work is performed that is not repetitive with very short work cycles and the workers are not restricted to one workplace. Furthermore, this source of variance reflects, for instance, postural differences due to fatigue over the course of the workday, and the worker's day-today and seasonal variability. The reliability of the measurement method also causes variation for the individual worker. Estimates of individual exposure may thus be subject to error from either source of variance or from a mixture of both sources of variance. The attenuation of the association between nonneutral trunk postures and back pain increases with the amount of error in the estimates (10). However, the magnitude of the underestimation at the individual level does not depend on the absolute value of any source of variance, but on the ratio of

1 Study Center on Work and Health, University of Amsterdam, Amsterdam, The Netherlands.

2 TNO Institute for Preventive Health Care, Leiden, The Netherlands.

3 Institute of Occupational Health, Erasmus University, Rotterdam, The Netherlands.

Reprint requests to: Dr Allard J van der Beek, Study Center on Work and Health, University of Amsterdam, Meibergdreef 15, 1105 AZ Amsterdam, The Netherlands. 
the within- and between-worker variance (11). To minimize bias, the absolute value of the between-worker variance should exceed that of the within-worker variance.

In many epidemiologic studies groups of workers with different occupations are compared, and therefore variance between occupational groups should be considered as a third source of variability. Analogous to the line of reasoning for the individual level, in the comparison of occupational groups the variance between groups should be larger than the variance within groups, because bias in risk estimates results from overlapping exposure distributions due to the variability of exposure within occupational groups (10).

The relative magnitude of the different sources of variance in exposure to toxic substances in air and the consequences for exposure assessment have been given comprehensive attention recently $(12,13)$. The subject has been introduced in the field of postural stress by Burdorf (8), who estimated the components of variance in observed exposure to nonneutral trunk postures. It appeared that the occupational group status was the principal source of variance for both trunk flexion and rotation, which is a desirable feature in the comparison of occupational groups. However, most of the workers in the study were restricted to one workplace. The relative magnitude of the different sources of variance may differ for subjects who work in more varying work situations. To gain a clear insight into the variability of exposure to postural stress becomes increasingly important, as this exposure is being assessed more and more often by means of computerized observational methods. To our knowledge it has never been reported that workers have been observed according to a well-considered measurement strategy. Moreover, in order to reduce the measurement effort, exposure data from observed workers are often used as an estimator of the exposure of unobserved workers (8). It has been illustrated that, when this strategy is applied, variability between workers leads to an underestimation of the magnitude of the association between exposure to nonneutral postures of the trunk and low-back pain (7).

Table 1. Age, height, and weight of 35 workers categorized into six occupational groups.

\begin{tabular}{|c|c|c|c|c|c|c|c|}
\hline \multirow[t]{2}{*}{$\begin{array}{l}\text { Occupational } \\
\text { group }\end{array}$} & \multirow{2}{*}{$\begin{array}{c}\text { Number } \\
\text { of } \\
\text { workers }\end{array}$} & \multicolumn{2}{|c|}{$\begin{array}{c}\text { Age } \\
\text { (years) }\end{array}$} & \multicolumn{2}{|c|}{$\begin{array}{l}\text { Height } \\
\text { (cm) }\end{array}$} & \multicolumn{2}{|c|}{$\begin{array}{l}\text { Weight } \\
(\mathrm{kg})\end{array}$} \\
\hline & & Mean & SD & Mean & SD & Mean & SD \\
\hline Truck drivers & 7 & 39 & 10 & 182 & 4 & 85 & 11 \\
\hline Garbage collectors & 8 & 34 & 11 & 178 & 5 & 79 & 21 \\
\hline Transport workers & 5 & 27 & 9 & 182 & 4 & 78 & 17 \\
\hline Warehouse workers & 5 & 28 & 3 & 178 & 13 & 79 & 32 \\
\hline Forklift truck drivers & 5 & 46 & 10 & 178 & 5 & 82 & 15 \\
\hline Nurses & 5 & 29 & 5 & 167 & 3 & 63 & 5 \\
\hline
\end{tabular}

To help identify the contribution of various risk factors to the development of musculoskeletal disorders, 2500 workers with different occupations will take part in a prospective epidemiologic study. Exposure to nonneutral postures of the trunk is one of the occupational risk factors that will be studied. The assessment of this exposure variable requires a well-defined measurement strategy, in which the different sources of variance in exposure should be taken into account. To obtain estimates of the variance components prior to the main study, a data base consisting of a considerable number of observed work postures, including trunk flexion and trunk rotation or lateroflexion, was analyzed. The aim of this study among workers who performed dynamic tasks in varying work situations was to estimate the contribution of the different sources of variance to the total variability of exposure to nonneutral postures of the trunk.

\section{Subjects and methods}

\section{Subjects}

The data base consists of exposure data from previously conducted studies in which 219 subjects with six different occupations were observed during a considerable part of the workday by means of the TRAC (task recording and analysis on computer) system. The subjects were randomly selected from all workers in their company with the same occupation, and each worker who was asked to participate voluntarily agreed to do so. It is a time-consuming process to combine data of different studies into a comparable format; thus data reduction was needed. In general, the workers observed for the longest period during the workday were selected. The population in the present study consisted of 35 workers; their characteristics are shown in table 1 . The first occupational group of seven truck drivers, who were selected from 40 truck drivers, performed pushing and pulling activities while loading and unloading the cargo. In the second occupational group eight collectors of garbage bags were selected from 116 studied garbage collectors. The work postures of the truck drivers and garbage collectors were recorded only during the loading-unloading task and the collection of garbage bags, respectively. The workers of the four occupational groups described below were observed irrespective of the task, with the exception of pauses. The third occupational group consisted of five transport workers, who manually loaded and unloaded miscellaneous goods. Another important task of these workers was sorting the goods according to area code. They were selected from 23 subjects who did the same work. In the fourth group most of the time was spent selecting ordered goods that were stored in a warehouse. These warehouse workers, five of them taken 
from 27 subjects, came from distribution centers in which electric cars were frequently used. While driving these cars, the workers were able to adopt an upright standing posture. The fifth occupational group consisted of five forklift truck drivers, who performed sedentary work and were selected from eight subjects in the same job. All of five nurses were included as the sixth occupational group. Their work mainly involved medical care, administration and domestic activities. The forklift truck drivers were restricted to one workplace (the cabin), but all of the other workers were, as a result of their mobility, observed in varying work situations.

\section{Observations}

Work postures were recorded by an observer using time sampling by means of TRAC (14). Every $15 \mathrm{~s}$, at an audible cue, several postural aspects were recorded (15), of which the trunk postures were relevant for this study. Flexion of the trunk was categorized into $<15,15-44$, $45-74$, and $\geq 75$ degrees. Since trunk flexion was rarely more than 44 degrees, the last three categories were later combined into the category $\geq 15$ degrees. Trunk rotation and lateroflexion was dichotomized into $0-29$ and $\geq 30$ degrees.

In this study four observers were involved. Three observers for the occupational groups of truck drivers, garbage collectors, and nurses, and the fourth for the transport workers, warehouse workers, and forklift truck drivers. Thus workers with the same occupation were always observed by the same observer. For all of the observers the training preceded the observations and was rounded off by a reliability test in which the coefficient kappa had to exceed 0.5 for all variables. (See reference 15.) The protocol at the workplace required that, if the observation period exceeded $20 \mathrm{~min}$, the observer rest for at least $20 \mathrm{~min}$ before starting a new period of observation. The aim was that the observation periods be randomly distributed over the workday so that the periods were representative for the full workday.

\section{Data analysis and statistics}

The availability of more than one measurement per worker permits an analysis of variance to estimate the relative magnitude of the within-worker and between-worker variance. Therefore, the observations were clustered in sustained periods of $10 \mathrm{~min}$, in which 40 time samples were recorded. The percentages of the 10 -min observation periods spent with trunk flexion and with trunk rotation or lateroflexion were used as the primary measures. For every worker, repeated measurements were selected as follows: six observation periods of $10 \mathrm{~min}$ for truck drivers and garbage collectors and 10 observation periods of $10 \mathrm{~min}$ for workers in the other occupational groups. The periods that were used for the analysis were randomly selected over the workday. The reason for the difference in the number of observation periods was that, for truck drivers and garbage collectors, fewer observations were available, as their postures were only recorded during one specific task. The four other groups were observed irrespective of the task, and it was considered that the work postures probably differed between tasks (ie, with the task factor additional variance was introduced). Therefore, separate analyses of variance were performed for these groups.

In order to evaluate whether the postural measures were normally distributed, the Kolmogorov-Smirnov statistic was calculated for every group. It appeared that three of the twelve distributions significantly deviated from normality. Since log-transformations did not reduce this number, the untransformed data were used for the analysis. It should be noted that the assumption of normality is not needed in the analysis of variance itself until F-statistics are calculated to obtain confidence intervals or to test hypotheses (16).

The two-tailed paired t-test was used to compare the exposure to nonneutral trunk postures during the selected 10-min observation periods with the exposure during all observations. Differences were accepted as statistically significant at $\mathrm{P}<0.05$. To estimate the variance components from the exposure data, the random effects model was used. A one-way analysis with repeated measurements was performed to estimate the components of the between- and within-worker variance. So that the contribution of the occupational group factor to the total variability of exposure to nommeutral trunk postures could be determined, this factor was included as an additional source of variance. The three different components of random variation were estimated by means of a nested two-way analysis of variance with repeated measurements. In this random model the workers were nested within the occupational group factor. Details of the underlying statistical assumptions and the mathematical structure of the analyses of variance have been given elsewhere (8). The data were analyzed by means of SAS (statistical analysis system) statistical software (Proc Nested).

\section{Results}

In table 2 the percentages of observed worktime with trunk flexion are given by occupational group. The differences in mean exposure to trunk flexion between all of the observations and the selected 10-min observation periods were not significant. Except for the transport workers, this difference did not exceed $1 \%$. The lastmentioned occupational group showed the largest variation among the workers for the selected observation peri- 
Table 2. Percentages of the worktime with trunk flexion during all observations and during the selected 10-min observation periods, by occupational group.

\begin{tabular}{|c|c|c|c|c|c|c|c|}
\hline \multirow[t]{2}{*}{ Occupational group } & \multicolumn{3}{|c|}{ All observations } & \multicolumn{4}{|c|}{ Selected observation periods } \\
\hline & $\mathrm{Na}^{\mathrm{a}}$ & $\begin{array}{l}\text { Mean } \\
(\%)\end{array}$ & SD & $\mathrm{N}^{\mathrm{b}}$ & $\begin{array}{c}\text { Mean } \\
(\%)\end{array}$ & $\mathrm{SD}$ & $\begin{array}{c}\text { Range } \\
(\%)\end{array}$ \\
\hline $\begin{array}{l}\text { Truck drivers } \\
\text { Garbage collectors }\end{array}$ & $\begin{array}{l}320 \\
490\end{array}$ & $\begin{array}{l}19.1 \\
27.1\end{array}$ & $\begin{array}{l}6.3 \\
7.7\end{array}$ & $\begin{array}{l}6 \\
6\end{array}$ & $\begin{array}{l}19.2 \\
26.3\end{array}$ & $\begin{array}{l}4.3 \\
6.5\end{array}$ & $\begin{array}{l}13.8-24.1 \\
17.5-35.8\end{array}$ \\
\hline $\begin{array}{l}\text { Transport workers } \\
\text { Warehouse workers } \\
\text { Forklift truck drivers } \\
\text { Nurses }\end{array}$ & $\begin{array}{l}671 \\
657 \\
681 \\
930\end{array}$ & $\begin{array}{l}23.0 \\
18.9 \\
10.5 \\
18.0\end{array}$ & $\begin{array}{l}7.0 \\
5.0 \\
3.2 \\
6.1\end{array}$ & $\begin{array}{l}10 \\
10 \\
10 \\
10\end{array}$ & $\begin{array}{l}25.3 \\
18.6 \\
10.3 \\
17.5\end{array}$ & $\begin{array}{l}9.9 \\
5.3 \\
3.2 \\
3.5\end{array}$ & $\begin{array}{r}12.8-38.0 \\
13.5-27.0 \\
5.3-13.3 \\
14.8-23.5\end{array}$ \\
\hline
\end{tabular}

a Nean number of recordings per worker.

b Number of 10-min observation periods (each period 40 recordings).

Table 3. Percentages of the worktime with trunk rotation or lateroflexion during all observations and during the selected 10-min observation periods, by occupational group.

\begin{tabular}{|c|c|c|c|c|c|c|c|}
\hline \multirow[t]{2}{*}{ Occupational group } & \multicolumn{3}{|c|}{ All observations } & \multicolumn{4}{|c|}{ Selected observation periods } \\
\hline & $N^{a}$ & $\begin{array}{c}\text { Mean } \\
(\%)\end{array}$ & $\mathrm{SD}$ & $N^{b}$ & $\begin{array}{c}\text { Mean } \\
(\%)\end{array}$ & $\mathrm{SD}$ & $\underset{(\%)}{\text { Range }}$ \\
\hline $\begin{array}{l}\text { Truck drivers } \\
\text { Garbage collectors }\end{array}$ & $\begin{array}{l}320 \\
490\end{array}$ & $\begin{array}{l}12.1 \\
16.1\end{array}$ & $\begin{array}{l}3.4 \\
5.3\end{array}$ & $\begin{array}{l}6 \\
6\end{array}$ & $\begin{array}{l}12.4 \\
15.5\end{array}$ & $\begin{array}{l}4.0 \\
4.8\end{array}$ & $\begin{array}{l}6.3-18.8 \\
8.2-20.0\end{array}$ \\
\hline $\begin{array}{l}\text { Transport workers } \\
\text { Warehouse workers } \\
\text { Forklift truck drivers } \\
\text { Nurses }\end{array}$ & $\begin{array}{l}671 \\
657 \\
681 \\
930\end{array}$ & $\begin{array}{r}11.8 \\
9.5 \\
11.2 \\
11.4\end{array}$ & $\begin{array}{l}3.0 \\
9.3 \\
3.3 \\
7.6\end{array}$ & $\begin{array}{l}10 \\
10 \\
10 \\
10\end{array}$ & $\begin{array}{r}11.3 \\
9.6 \\
11.5 \\
9.7\end{array}$ & $\begin{array}{r}2.2 \\
10.7 \\
3.9 \\
7.1\end{array}$ & $\begin{array}{l}7.5-12.8 \\
2.3-27.5 \\
6.6-15.3 \\
4.3-21.8\end{array}$ \\
\hline
\end{tabular}

a Mean number of recordings per worker.

b Number of $10-$ min observation periods (each period 40 recordings).

Table 4. Absolute (variance component) and relative (\%) contribution to the total variability of exposure to trunk flexion and trunk rotation or lateroflexion among 15 workers (8 garbage collectors and 7 truck drivers)

\begin{tabular}{lcccccc}
\hline $\begin{array}{l}\text { Source } \\
\text { of variance }\end{array}$ & \multicolumn{2}{c}{ Flexion } & & \multicolumn{3}{c}{$\begin{array}{c}\text { Rotation or } \\
\text { lateroflexion }\end{array}$} \\
\cline { 2 - 3 } \cline { 5 - 6 } & $\begin{array}{c}\text { Variance } \\
\text { component }\end{array}$ & $\%$ & & \multicolumn{2}{c}{$\begin{array}{c}\text { Variance } \\
\text { component }\end{array}$} & $\%$ \\
\hline $\begin{array}{l}\text { Between workers } \\
\begin{array}{l}\text { Between observation } \\
\text { periods for the same }\end{array}\end{array}$ & 25.8 & 20.1 & & 11.2 & 16.2 \\
\begin{tabular}{l} 
worker \\
\hline
\end{tabular} & 102.2 & 79.9 & & 57.6 & 83.8 \\
\hline
\end{tabular}

ods. The mean exposure to trunk flexion for the truck drivers and garbage collectors was about one-fifth and one-fourth of the time, respectively. The differences among the other occupational groups were somewhat larger (ranging from 10.3 to 25.3 for the selected observation periods).

For exposure to trunk rotation or lateroflexion, the same overall picture appeared. No significant differences in mean exposure between all of the observations and the selected 10-min observation periods were found (table 3). Again, only for one occupational group (the nurses) was this difference more than $1 \%$. The differences in mean exposure to trunk rotation or lateroflexion among the occupational groups were small; the transport workers, warehouse workers, forklift drivers, and nurses were almost equally exposed (from 9.6 to $11.5 \%$ for the selected observation periods). Within the occupational groups of warehouse workers and nurses the differences among the workers were large, whereas the transport workers were the most homogeneous with respect to the individual mean exposure.

Table 4 shows that, in the population of 15 workers (the truck drivers and garbage collectors) the withinworker variance accounted for around $80 \%$ of the total variability of exposure to nonneutral postures of the trunk. This finding indicated that the differences in the mean exposure to these trunk postures were much smaller between the workers than for the individual workers. Table 5 presents the results of the nested analysis of variance in which the contribution of the occupational group factor to the total variability of exposure to nonneutral trunk postures was also estimated. For exposure to trunk flexion the variance between groups (15.2\%) was considerably smaller than the variance within the two occupational groups, which was mainly caused by the variability of the individual workers. For exposure to 
Table 5. Absolute (variance component) and relative (\%) contribution to the total variability of exposure to trunk flexion and trunk rotation or lateroflexion in two occupational groups (8 garbage collectors and 7 truck drivers).

\begin{tabular}{|c|c|c|c|c|}
\hline \multirow[t]{2}{*}{$\begin{array}{l}\text { Source } \\
\text { of variance }\end{array}$} & \multicolumn{2}{|c|}{ Flexion } & \multicolumn{2}{|c|}{$\begin{array}{l}\text { Rotation or } \\
\text { lateroflexion }\end{array}$} \\
\hline & $\begin{array}{l}\text { Variance } \\
\text { component }\end{array}$ & $\%$ & $\begin{array}{l}\text { Variance } \\
\text { component }\end{array}$ & $t^{\%}$ \\
\hline Between groups & 20.9 & 15.2 & 2.2 & 3.1 \\
\hline $\begin{array}{l}\text { Between workers, } \\
\text { within groups }\end{array}$ & 14.6 & 10.6 & 10.0 & 14.3 \\
\hline $\begin{array}{l}\text { Between observation } \\
\text { periods for the same } \\
\text { worker }\end{array}$ & 102.2 & 74.2 & 57.6 & 82.6 \\
\hline
\end{tabular}

trunk rotation or lateroflexion the division of the occupational groups was even less informative, almost all variability $(96.9 \%)$ was within the groups.

The results of the analysis of variance for the population of 20 workers (the transport workers, warehouse workers, forklift drivers, and nurses) with 10 repeated observation periods per worker are presented in table 6 . The within-worker variation was the largest source of variance for both exposure to trunk flexion and trunk rotation or lateroflexion. In table 7 the total variability of exposure to nonneutral postures of the trunk has been divided into three sources of variance. The variance between groups contributed less than $15 \%$ to the total variability of exposure to trunk flexion. For exposure to trunk rotation and lateroflexion the negative value of the estimated variance component between occupational groups was the most striking result, because a variance component is by definition positive. However, this negative value can be considered as evidence that the real value is zero and that the four occupational groups were equally exposed to trunk rotation and lateroflexion.

\section{Discussion}

In this study among workers who performed dynamic tasks in varying work situations the different components of variance in exposure to nonneutral trunk postures were estimated. The within-worker variance contributed around $80 \%$ to the total variability of exposure to both trunk flexion and trunk rotation or lateroflexion.

\section{Subjects}

One assumption of the random effects model is that the groups of workers consist of a random sample of all possible workers. The workers in this study were not randomly selected; instead they were chosen on the basis
Table 6. Absolute (variance component) and relative (\%) contribution to the total variability of exposure to trunk flexion and trunk rotation or lateroflexion among 20 workers ( 5 transport workers, 5 warehouse workers, 5 forklift truck drivers, and 5 nurses).

\begin{tabular}{lccccc}
\hline $\begin{array}{l}\text { Source } \\
\text { of variance }\end{array}$ & \multicolumn{2}{c}{ Flexion } & & \multicolumn{2}{c}{$\begin{array}{c}\text { Rotation or } \\
\text { lateroflexion }\end{array}$} \\
\cline { 2 - 3 } & $\begin{array}{c}\text { Variance } \\
\text { component }\end{array}$ & $\%$ & & $\begin{array}{c}\text { Variance } \\
\text { component }\end{array}$ & $\%$ \\
\hline $\begin{array}{l}\text { Between workers } \\
\begin{array}{l}\text { Between observation } \\
\text { periods for the same } \\
\text { worker }\end{array}\end{array}$ & 43.0 & 19.8 & & 30.5 & 24.6 \\
\hline
\end{tabular}

Table 7. Absolute (variance component) and relative (\%) contribution to the total variability of exposure to trunk flexion and trunk rotation or lateroflexion in four occupational groups ( 5 transport workers, 5 warehouse workers, 5 forklift truck drivers, and 5 nurses).

\begin{tabular}{lccccc}
\hline $\begin{array}{l}\text { Source } \\
\text { of variance }\end{array}$ & \multicolumn{2}{c}{ Flexion } & & \multicolumn{2}{c}{$\begin{array}{c}\text { Rotation or } \\
\text { lateroflexion }\end{array}$} \\
\cline { 2 - 3 } \cline { 5 - 6 } & $\begin{array}{c}\text { Variance } \\
\text { component }\end{array}$ & $\%$ & & $\begin{array}{c}\text { Variance } \\
\text { component }\end{array}$ & $\%$ \\
\hline $\begin{array}{l}\text { Between groups } \\
\begin{array}{l}\text { Between workers, } \\
\text { within groups }\end{array}\end{array}$ & 31.8 & 14.2 & & $(-8.2)$ & $(0)$ \\
$\begin{array}{l}\text { Between observation } \\
\text { periods for the same } \\
\text { worker }\end{array}$ & 17.9 & 8.0 & & $(37.0)$ & $(28.4)$ \\
\hline
\end{tabular}

of the number of observed work postures. However, there were no major differences in the personal characteristics, exposures, or musculoskeletal symptoms between the selected workers and those who were not selected, and therefore the assumption of randomness was not violated by this selection criterion.

The transport workers, warehouse workers, and forklift truck drivers originated from companies in the hauling industry. They were grouped a priori into different occupations because it was observed that these workers moved goods differently (walking, standing, and sitting, respectively). It appeared that this grouping on job title, which could have been more successful for trunk flexion, was totally useless for rotation and lateroflexion because it did not distinguish between the groups. This finding emphasizes the importance of deciding for every separate variable whether it is allowed to assign the workers to different occupational groups.

\section{Observations}

Although all four of the observers had a considerable period of training and were only allowed to make obser- 
vations at the workplace after they passed a reliability test, some interobserver variability may have been introduced. However, the possible interobserver variability would have appeared in the between-group variance because all of the workers with the same occupation were observed by the same observer. The between-group variance proved not to be an important source of variance; thus error due to interobserver variability was probably negligible.

Although the observations were randomly selected as much as possible over the day (with the exception of pauses), it remains unknown whether the distribution over the time of day of the observations was representative for the full workday. Bias may have been introduced when this distribution was not random for each worker. It was possible to examine this consideration especially in relation to the work tasks of the subjects because our data base also contains data of a second observer, who observed, among other things, tasks during the full workday. Because the two observers worked simultaneously, the task according to the second observer is known at every time-sampled observation of the work posture. Therefore, it was possible to compare the percentages of time that tasks were performed during postural observation with the percentages of time during the full workday. For hardly any task of the occupational groups was a significant difference found; this result indicates that the postural observation periods were representative of the full workday. Furthermore, for every worker, repeated measurements ( 6 or 10 observation periods of $10 \mathrm{~min}$ ) were randomly selected from the available observations. It can be seen in tables 2 and 3 that the selected periods of $10 \mathrm{~min}$ were representative for the observed parts of the workday (all observations).

The work postures of four occupational groups were observed during all of the tasks, with the exception of pauses. For these groups variability in relation to work tasks could theoretically be assessed. However, for three out of the four groups either tasks alternated quickly or the job was limited to one main task, which made it impossible to select enough 10-min observation periods. Thus it remains unknown whether the exposure variability arose from variance between or within tasks. It is considered that future studies should focus on variability in relation to work tasks as well.

\section{Sources of variance}

For within worker variance (ie, between observation periods of $10 \mathrm{~min}$ ) a highly varied exposure to nonneutral postures of the trunk was observed. The within-worker variance was always a multiple of the between-worker variance. Consequently, the ratio of both sources of variance was never smaller than 1, as was reported by Burdorf (8). When accounting for occupational group status, the same author found that the largest source of variance was between occupational groups, neither was this finding confirmed in our study. We believe that the most important difference between both studies was that, in our study, most of the workers were observed in different work situations, while most of the workers in Burdorf's study were restricted to one workplace. However, it should be noted that in both studies the real value of the within-worker variance was probably underestimated, because day-to-day variability could not be taken into account in either case.

For the highly stereotyped work of supermarket checkers the coefficients for trunk flexion were smaller for within-worker variance than for between-worker variance (17). Back flexion angles of visual artists, who worked on large drawings, showed more within-worker variation than the corresponding angles of those who worked on detailed drawings (18). Furthermore, the within-worker variability of the back flexion angles was considerably larger when the workers adopted a standing posture instead of being able to perform the same task in a seated position (19). In general, when work becomes more dynamic or less repetitive and stereotyped, the amount of within-worker variation increases. The finding that the within-worker variance was the most important source of variability cannot only be explained by the fact that there were no consistent work cycles in the observed work situations. First, at different locations, a large variety of goods (and patients for the nurses) had to be handled, and each were handled differently. Second, in particular for the nurses, there were considerable differences in exposure between tasks. However, it is unlikely that the same goods or patients were handled differently due to fatigue over the course of the day, because no evidence of any temporal trend could be found.

For the transport workers, warehouse workers, forklift drivers, and nurses the group means of exposure to trunk rotation or lateroflexion showed a small range (between 9.6 and 11.5, table 3) and the variability among particularly the warehouse workers and nurses was large (coefficient of variation 111 and $73 \%$, respectively). The variance component between these four occupational groups was negative for this exposure variable. Since a variance component is by definition positive, an explanation is needed. The fact that a variance component can become negative has nothing to do with, for instance, assumed normality; instead it is solely a consequence of the data and the method. It has been stated that a negative variance component is an indication that the true value is zero (16). Suppose that all of the groups were uniformly exposed; in other words, the expected value of the mean exposure for each group is the same and, therefore, the same as the mean for the entire population $[E(\vec{x})=\mu]$. The measured group mean can be considered the outcome of a random trial and has an expected associated 
variance $\left[\sigma^{2}(\bar{x})=\sigma^{2}(x) / n\right]$. It is possible that merely by chance the measured group means were not as widely divergent as expected; in other words the variability of group means $\left[\sigma^{2}(\bar{x})\right]$ was substantially smaller than expected on the basis of the variability of workers $\left[\sigma^{2}(\mathrm{x}) / \mathrm{n}\right]$. The result of this coincidence is a negative variance component, which indicates the absence of differences between the groups. An undesirable aspect of the use of zero in place of the negative value of the variance component is that the other variance components are no longer unbiased estimates (16).

\section{Measurement strategy}

In the design of measurement strategies for assessing occupational exposure to nonneutral trunk postures, insight is needed into the contribution of the different components of variance to the total variability of exposure. Many epidemiologists are concerned with estimating the risk for back pain associated with exposure to flexed and rotated postures of the trunk. However, the effect of a relatively large exposure variability for individual workers on risk estimates can be considerable due to misclassification. This nondifferential misclassification of exposure causes an underestimation of the exposure-response relationship. The magnitude of the resultant bias at the individual level can be obtained with the formula of Liu et al (20), in which the ratio of the within- and betweenworker variance is included. For both postural measures of our study the bias in a regression coefficient would be around $30 \%$ if all of the workers (15 and 20 , respective$1 y$ ) were analyzed together. This bias can simply be reduced by an additional number of repeated measurements per worker, which basically means decreasing the ratio of the within- and between-worker variance by reducing the former. In general, the absolute magnitude of the within-worker variance can be reduced by (i) increasing the length of the observation periods (ie, increasing the number of recordings per period), (ii) increasing the number of repeated observation periods, or (iii) improving the reliability of the measurement method. The last-mentioned approach probably yields the least effect (8). Both of the other approaches lead to the same conclusion (ie, more measurements per worker in order to obtain a more precise estimate of exposure). Generally the first approach would be the most practical to accomplish, but the occurrence of any particular temporal trend concerning exposure to postural stress may require that the second approach has to be followed. Especially exposure variability during short intervals (eg, a daily work peak) should not be ignored when the measurement strategy is determined. An increase in the between-worker variance can be realized by the introduction of external referents with substantial differences in the level of exposure.
In the comparison of occupational groups the between-group variance should be the most important source of exposure variability. To increase the betweengroup variance, one should select the groups that have a large contrast in exposure to both postural measures in the study population. If this strategy proves insufficient, it may be necessary to select an external reference group with maximal contrast in exposure. The variation within groups can be decreased by selecting homogeneous groups with exposures that vary relatively little between workers and for individual workers. Furthermore, an increased sample from the population under study and more measurements per worker reduce the within-group variance (between- and within-worker variance, respectively).

In some situations it might be useful to measure according to a task-oriented strategy requiring a different number of observations for each task. In this strategy the number of observations per task is determined by the variation within the tasks (and not by the duration of the tasks). For homogeneous tasks with short cycles a limited number of observed postures may be enough to describe the worker's exposure (21), while dynamic tasks in varying work situations require more observations. In the present study, however, this measurement strategy was not suitable for workers who were observed during more than one task because either their work consisted of a frequent alternation of tasks or because tasks other than the main task hardly occurred.

\section{Concluding remarks}

For workers who performed rather dynamic tasks in varying work situations, by far the most important source of variance in exposure to nonneutral trunk postures was the within-worker variance. It is assumed that unbiased estimates of exposure are difficult to achieve for individual workers. Thus the measurement strategy with respect to the assessment of individual exposure to postural stress requires many repeated observations per worker. In the case of the estimation of an exposure-response relationship at the level of occupational groups, it is recommended to include groups with maximal contrast in exposure and to reduce the within-group variance by selecting homogeneously exposed workers.

\section{Acknowledgments}

The authors would like to thank Paul Kuijer, Arthur Stassen, Olivier Maes, and especially Ingrid Braam for their contributions to this study. 


\section{References}

1. Frymoyer JW, Pope MH, Constanza MC. Epidemiologic studies of low back pain. Spine 1980;5:419-23.

2. Anderson GBJ. Epidemiologic aspects of low-back pain in industry. Spine 1981;6:53-60.

3. Keyserling WM, Punnett L, Fine LJ. Trunk postures and back pain: identification and control of occupational risk factors. Appl Ind Hyg 1988;3:87-92.

4. Riihimäki H. Low-back pain, its origin and risk indicators. Scand J Work Environ Health 1991;17:81—90.

5. Damkot DK, Pope MH, Lord J, Frymoyer JW. The relationship between work history, work environment and low back pain in men. Spine 1984;9:395-9.

6. Gilad I, Kirschenbaum A. About the risks of back pain and work environment. Int J Ind Ergon 1986;1:65-74.

7. Punnett L, Fine LJ, Keyserling WM, Herrin GD, Chaffin DB. Back disorders and nonneutral trunk postures of automobile assembly workers. Scand J Work Environ Health 1991;17: $337-46$.

8. Burdorf A. Sources of variance in exposure to postural load on the back in occupational groups. Scand J Work Environ Health $1992 ; 18: 361-7$.

9. Rappaport SM. Exposure assessment strategies. In: Rappaport SM, Smith TJ, editors. Exposure assessment for epidemiology and hazard control. Chelsea, MI: Lewis Publishers, 1991: $219-49$.

10. Burdorf A. Bias in risk estimates from variability of exposure to postural load on the back in occupational groups. Scand J Work Environ Health 1993;19:50_4

11. Heederik D, Boleij JSM, Kromhout H, Smid T. Use and analysis of exposure monitoring data in occupational epidemiology: an example of an epidemiological study in the dutch animal food industry. Appl Occup Environ Hyg 1991;6:45864.

12. Rappaport SM. Assessment of long-term exposure to toxic substances in air. Am Occup Hyg 1991;35:61-121.
13. Kromhout H, Symanski E, Rappaport M. A comprehensive evaluation of within- and between-worker components of occupational exposure to chemical agents. Am Occup Hyg 1993; $37: 253-70$.

14. Ridd JE, Nicholson AS, Montan AJ. A portable microcomputer based system for 'on site' activity and posture recording. In: Megaw ED, editor. Contemporary ergonomics '89: proceedings of the Ergonomics Society Conference 1989. London: Taylor \& Francis, 1989:366-71.

15. van der Beek AJ, Van Gaalen LC, Frings-Dresen MHW. Working postures and activities of lorry drivers: a reliability study of on-site observation and recording on a pocket computer. Appl Ergon 1992;23:331-6.

16. Searle SR, Casella G, McCulloch CE. Variance components. New York, NY: John Wiley \& Sons, 1992.

17. Harber P, Bloswick D, Peña L, Beck J, Lee J, Baker D. The ergonomic challenge of repetitive motion with varying ergonomic stresses: characterizing supermarket checking work. J Occup Med 1992;34:518-28.

18. Chang WS, Bejjani FJ, Chyan D, Bellegarde M. Occupational musculoskeletal disorders of visual artists: a questionnaire and video analysis. Ergonomics 1987;30:33- 46.

19. Åaras A, Westgaard RH, Stranden E. Postural angles as an indicator of postural load and muscular injury in occupational work situations. Ergonomics 1988;31:915-33.

20. Liu K, Stamler JA, Dyer A, McKeever J, McKeever P. Statistical methods to assess and minimize the role of intra-individual variability in obscuring the relationship between dietary lipids and serum cholesterol. J Chronic Dis 1978;31:399 418

21. Mattila M, Karwowski W, Vilkki M. Analysis of working postures in hammering tasks on building construction sites using the computerized OWAS method. Appl Ergon 1993; $24: 405-12$.

Received for publication: 26 April 1994 